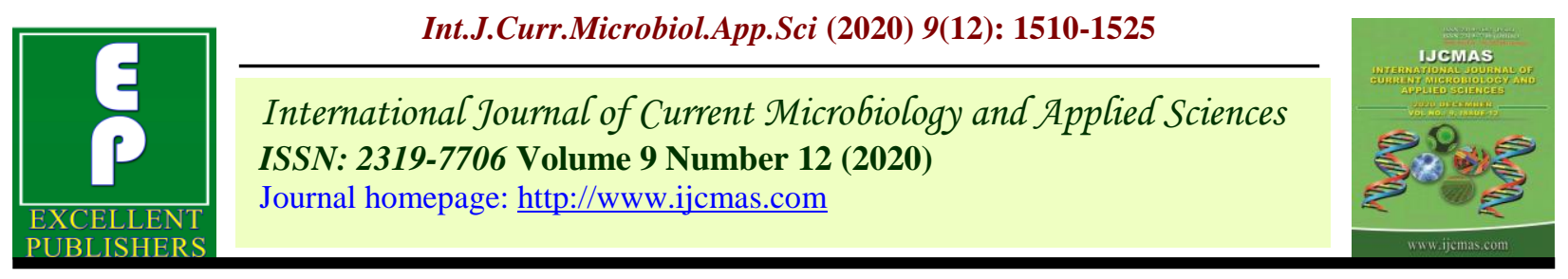

Original Research Article

https://doi.org/10.20546/ijcmas.2020.912.180

\title{
Quality Analysis of Prepared Mixed Wheat Flour
}

\author{
Bhanu Pratap Singh* and Pradeep Srivastava \\ School of Biochemical Engineering, Indian Institute of Technology (BHU), Varanasi, India \\ *Corresponding author
}

\begin{tabular}{|l|}
\hline $\begin{array}{l}\text { Ke y w or d s } \\
\text { Quality analysis, } \\
\text { Mixed wheat flour }\end{array}$ \\
\hline Article Info \\
\hline $\begin{array}{l}\text { Accepted: } \\
\text { 12 November } 2020 \\
\text { Available Online: } \\
10 \text { December } 2020\end{array}$ \\
\hline
\end{tabular}

\author{
A B S T R A C T
}

\begin{abstract}
Gluten free bread is highly acceptable to the typical consumer to be diagnosed with celiac disease and gluten intolerance. The main problem with the gluten free bread is compromised properties in terms of texture, shape, size with other quality attributes, which are due to the lack of gluten during bread doughing. In that case mixed wheat flour is a better option. However there is ample scope to enhance the nutritional value of the bread both quantitatively and qualitatively using nutritious food ingredients. Rice flour has been found to be one of the most suitable cereal grain flours for preparing foods for celiac disease (CD) patients with various nutritional qualities. Wheat is unique in that when its flour is mixed with a limited amount of water it forms visco elastic dough. These visco elastic properties enable the dough to hold the $\mathrm{CO} 2$ gas produced by yeast or baking powder and to expand to leavened baked products like bread with a light airy texture. These properties of the wheat dough are attributed to its gluten proteins. Rice has no such proteins. Hence, the production of baked goods from rice that have similar texture and eating quality to those from wheat is a real challenge. The current study has been made to blend the blend of rice \& wheat flour and to study the quality analysis of prepared mixed wheat flour.
\end{abstract}

\section{Introduction}

Bread is a staple food prepared from dough of flour and water, usually by baking. It is a dietary product obtained from the fermentation and the subsequent baking of dough mainly made of cereal flour and water, made in many different ways and sometimes enriched with typical regional ingredients. Proportions of types of flour and other ingredients vary widely, as do modes of preparation. As a result, types, shapes, sizes and texture so of breads differ around the world. Bread may be leavened by processes such as reliance on naturally occurring sourdough microbes, chemicals, industrially produced yeast, or high-pressure aeration. The bread formula consists of refined flour, fat, sugar and other additives. It is well documented that most of the ingredients used in commercial bread lack important nutrients. The refined flour lacks in dietary fiber and micronutrients which are important health promoting components. There is a growing awareness among the consumers regarding the constituents that affect health both positively and negatively. Number of such health conscious consumers is fast increasing and so is the health food industry. New foods with new health claims are flooding the market to meet the diverse demands of consumers. However, there is ample scope to enhance the nutritional value of breads both quantitatively and qualitatively using nutritious food ingredients such as millets. There have been reports of bread made from 
blend of other flour such as rice, composite flour of wheat, plantain and soybeans, sunflower seed flour, flax seed, composite flour of wheat, barnyard millet, proso millet and finger millet. (Uma Ballolli et al., 2014).

Gluten-free breads are usually characterized by deficient quality characteristics as compared to wheat breads. Problems related to volume and crumb texture are associated with gluten-free breads even when rice flour is used, which seems to be the best raw material for this type of bread. The potential use of cyclo-dextrin glycosyl transferase (C G Tase) as a rice bread improver is presented. The effect of CGTase addition to rice flour on dough rheology and bread quality was investigated. In addition, an experimental design was developed to optimize the levels of CGTase, hydroxyl propyl methyl cellulose (HPMC), and oil. The addition of CGT as produced is duction in the dough consistency and also in the elastic modulus. With regard to the rice bread quality, better specific volume, shape index, and crumb texture were obtained. The amount of cyclodextrins in the bread crumb was quantified to explain the action of this enzyme. The data indicate that the improving effect of the CGTase results from a combination of its hydrolyzing and cyclizing activities, the latter being responsible for the release of cyclodextrins, which have the ability to form complexes with lipids and proteins (Hardeep Singh Gujral et al., 2003).

Rice is rich in genetic diversity, with thousands of varieties grown throughout the world. Rice cultivation is the principal activity and source of income for about 100 million households in Asia and Africa. Rice has potential in a wide range of food categories. Rice, Oryza sativa $(2 \mathrm{n}=24)$ belonging to the family Gramineae and subfamily Oryzoidesis the second most important cereal crop and staple food for more than half of the world's population. Rice is a grain belonging to the grass family. It is related to other grass plants such as wheat, oats and barley which produce grain for food and are known as cereals. Rice refers to two species (Oryza sativa and Oryza glaberrima) of grass, native to tropical and subtropical south eastern Asia and to Africa, which together provide more than one-fifth of the calories consumed by humans. Rice protein, which comprises up to eight per cent of the grain, has a special benefit as it has eight of the essential amino acids in a delicately balanced proportion (Umadevi, 2014).

Rice flour (also rice powder) is a form of flour made from finely milled rice. It is distinct from rice starch, which is usually produced by steep in grice in lye. Rice flour may be made from either white rice or brown rice. Rice flour is functional food. (Suresh Chandra, Samsher 2013). Protein quality of rice surpasses that of wheat and corn while it is just inferior to oats. Also, rice protein is hypoallergenic and contains good quantity of lysine. Thus it may act as a suitable ingredient for infant food formulations while adding variety to the restricted diets of children with food allergies. Amino acid profile of rice protein was better than casein and soy protein isolate in fulfilling the amino acid requirements for 2-5 years old children. (Arpita Das et al., 2011)

Wheat is unique in that when is flour is mixed with a limited amount of water it forms a visco elastic dough. These visco elastic properties enable the dough to hold the $\mathrm{CO} 2$ gas produced by yeast or baking powder and to expand to leavened baked products like bread with a light airy texture. These properties of the wheat dough are attributed to its gluten proteins. Rice has no such proteins. Hence, the production of baked goods from rice that have similar texture and eating quality to those from wheat is a real 
challenge. Some form of hydro colloid (water-holding biopolymer) is added invariably when rice flour is used in wheatbased baked food products. The hydro colloid increases the viscosity of the dough and improves its gas holding properties and it also act as a binder and helps to prevent the product from crumbling (Tharise et al., 2013).

Rice flour also has been found to be one of the most suitable cereal grain flours for preparing foods for celiac disease (CD) patients. For genetically susceptible individuals, the ingestion of gluten

Also related proteins trigger an immunemediated enteropathy known as celiac disease. The symptoms of $\mathrm{CD}$ include teatorrhea, abdominal discomfort, weight loss or gain, tiredness, anemia, and severe diarrhea. Currently, the prevalence of CD is estimated to affect one in 100 people worldwide. The suitability of the rice flour is attributed to its low level of pro amines compared with that of wheat flour. Optimal rice bread formulations for CD patients have been developed, which meet wheat bread reference standards for specific volume, crumb and crust color, firmness and moisture. Rice bread in its earliest stage had small amount of rice flour added to replace some wheat flour in the formula, but now bread made out of $100 \%$ rice flour is developed and sold in retail stores. The $100 \%$ rice flour bread could some what mislead consumers since some rice bread add up to $17 \%$ vital gluten extracted from wheat as a supplemental ingredient in their formula to improve bread-making properties; others use various food gums, emulsifiers, and enzymes,instead.Onlythelatter,thus, couldberef erredtoastheso-called"gluten-free"ricebread in a strict sense. (Myoung Hu Kim 2013).

Bread is a staple food in many homes however upon diagnosis with celiac disease traditional wheat based breads are no longer an option for consumers. One of many challenges to individuals with celiac disease is the increased cost of gluten-free foods. On average gluten-free products are approximately $240 \%$ more expensive than their gluten-based counter parts. Further studies showed that $56.5 \%$ of participants reported it was difficult to find gluten-free food outside the home, while $75.3 \%$ of participants reported that quality of glutenfree products was a significant concern. Quality and availability of gluten-free foods to adolescents in schools cause adolescent noncompliance to gluten free diet. Thus appealing gluten-free foods must be available in schools or else Celiac will be unable to maintain a gluten-free diet (Annika Olsson and C. S k hold brand 2008).

Celiac disease is a condition in which the mucous membrane of the small intestine of gluten- intolerant people is damaged by gluten, resulting in poorly absorption of nutrients and, consequently, weight loss, diarrhea, anemia, fatigue, flatulence, deficiency of folate and osteopenia. The first description of the disease was made more than 100 years ago by Samuel Gee, as a "celiac disorder", defined as a chronic indigestion occurring in people of all ages, particularly in one-to-five year's old children (Ana Cristina Ballesteros Lopez et al., 2004).

Gluten is a proteinaceous material that can be separated from flour when the starch and other minor components of the flour are removed by washing out under running water. The resulting gluten contains approximately 65\% water. On a dry matter basis, gluten contains $75-86 \%$ protein, the remainder being carbohydrate and lipid, which are held strongly within the gluten-protein matrix. Gluten contains the protein fractions glutenin and gliadin. The former is a rough, rubbery mass when fully hydrated, while gliadin produces a viscous, fluid mass on hydration. Gluten, therefore, exhibits cohesive, elastic 
and viscous properties that combine the extreme soft the two components. The gluten matrix is a major determinant of the properties of dough (extensibility, resistance to stretch, mixing tolerance, gas holding ability), enclosing the starch granules and fiber fragments.

The main objectives include Preparation of rice flour \& its quality analysis. Preparation of bread with the blend of rice \& wheat flour. Study the quality analysis of prepared mixed wheat flour.

Ranasalva and Visvanathan (2014) studied the Development of bread from fermented pearl millet flour. The probiotic bacteria are found to get developed in the spontaneously fermented pearl millet. Bakery products are used as a vehicle for incorporation of different nutritionally rich ingredients. Fortification of wheat flour with non-wheat proteins increases protein quality by improving its amino acid profiles. The anti-nutrients phytic acid was reduced from $858.4 \mathrm{mg} / 100 \mathrm{~g}$ in the raw pearl millet to $380.3 \mathrm{mg} / 100 \mathrm{~g}$ in the cooked fermented pearl millet. Tannin did not show any reduction in its amount after cooking and fermenting the pearl millet from the raw pearl millet.

Lynda Dykes et al., (2014).studied the Prediction of total phenols, condensed tannins, and 3- deoxyanthocyanidins in sorghum grain using near-infrared (NIR) spectroscopy. There ported high phenolic levels in sorghum have led an interest from sorghum breeding programs in developing and identifying germplasms with high phenolic levels, which require screening a large number of samples to find those with the highest levels. Since wet chemistry screening methods are slow, expensive, and destructive, the use of NIR calibration curves could be an alternative. The objectives of this project were to determine the variation range in total phenols, condensed tannins, and 3- deoxyanthocyanidin levels in a diverse set of sorghum genotypes and to assess the predictive value of NIR curves to estimate these compounds in sorghum.

Myoung Ho Kim (2013) reviewed on Rice flour manufacturing and utilization. The review aims to provide information on rice flour utilization and manufacturing with some fundamental subjects in the area of size reduction.

Ratnavathi and Patil (2013) reviewed the Sorghum utilization as food. This review describes the utilization of sorghum as a food in different countries, India and Africa and its nutritional value and health benefits obtained from sorghum. The various foods prepared from sorghum are given in the review. The nutritional enhancement of the sorghum with other cereals also is given. Preparation of sweet sorghum syrup and its nutritive value is explained.

Tharise (2013) studied the Evaluation of physico-chemical and functional properties of composite flour from cassava, rice, potato, soybean and xanthan gum as alternative of wheat flour.

The physical, chemical and functional properties of the composite flours from rice, cassava flour, soybean flour, potato starch and xanthan gum were determined by cassava and soybean flours and also potato starches because in the study the rice flour and xanthan gum were in constant level. The higher level of soybean flour will increase the protein and fat content in composite flours.

UMA Ballolli et al., (2013) studied the Development and quality evaluation of foxtail millet (Setariaitalica L.) incorporated breads. Foxtail millet [Setaria italica (L.)] is an important underutilized millet grain, grown in various parts of India. It grows well even under adverse agro climatic conditions. It is 
good source of dietary fiber and $B$ carotene. Foxtail millet incorporated breads were developed by incorporating foxtail millet flour at 10,30 and 50 per cent level in the recipe. Height of the breads affected significantly at 50 percent incorporation of foxtail millet flour. Value addition to breads with foxtail millet resulted in significant change in colour of both crust and crumb. Crumb colour changed from white to dull yellowish with increased incorporation of millet flour. The highest $\mathrm{L}$ value was found for 50 per cent (67.24) incorporated breads followed by control (53.56), 30 per cent (48.47) and 10 per cent (40.86).

Umadevi et al., (2012) studied on the Ricetraditional medicinal plant in India. Health benefits of rice include providing fast and instant energy, good bowel movement, stabilizing blood sugar levels and providing essential source of vitamin B1 to human body. Other benefits include skin care, resistance to high blood pressure, dysentery and heart diseases. Rice is the staple food in most of the countries and it is an important cereal crop that feeds more than half of the world's population.

Arpita Das et al., (2011) reviewed the Cereal based functional food of Indian subcontinent. In the developed countries, due to large obesity problem and also for maintaining normal and sound health, different formulations and activities are coming up, specially delivering soluble fibres to the consumers via different foods like cereals and cereal products containing antioxidants. Cereals like wheat, maize, rice, oats etc. are now employed in preparation of food that are similar in appearance to conventional food and used in normal diet but have an added advantage of aiding physiological functions along with providing nutrition. Eating habits can drastically reduce healthcare expenditures if individuals were to modify their diets based on an existing knowledge of nutrition. In today's world the development and utilization of different cereal based functional foods is a challenging task. Invention of newer technologies for processing of cereals to improve their nutritional value vis-à-vis their acceptability by the end users will be the focus area in the near future.

Celiac disease is a genetic autoimmune disorder found in approximately 1 of 133 people in the United States. Individuals with celiac disease react to prolamin fractions found in wheat, rye, and barley (Niewinski, 2008). Increasing diagnoses of celiac disease has created a rise in demand for gluten-free products. Gluten-free bread has undesirable properties such as reduced loaf volume and brittle, hard texture. Recent studies have reported that quality of gluten-free products was a significant concern to individuals with celiac disease.

Hrdeep Singh Gujral et al., (2003) studied the Effect of cyclodextrinase on dough rheology and bread quality from rice flour. Gluten-free breads are usually characterized by deficient quality characteristics as compared to wheat breads. Problems related to volume and crumb texture are associated with gluten-free breads even when rice flour is used, which seems to be the best raw material for this type of bread. The potential use of cyclodextrin glycosyl transferase (CGTase) as a rice bread improver is presented.

Arun Chandra Shekhar and Majhar (1999) reviewed the biochemical basis and implications of grain strength in sorghum and maize. This review deals with the biochemical basis and implications of hardness and grain strength in sorghum and maize. Grain hardness affects various aspects of the growth and processing of cereal grain from resistance to fungal infection to cooking quality. It is clear that the prolamins play an important role 
with the $\gamma$-prolamins being the most important. It would appear that these prolamins help shape the protein bodies and form disulphide bonds within themselves or with.

\section{Materials and Methods}

The experiments were conducted in Food Processing and Preservation Laboratory in the Department of Food Technology, Harcourt Butler Technical University, Kanpur. Raw materials viz., broken and brown rice grain, wheat flour, milk powder, vegetable fat, sugar, salt etc.

\section{Raw materials}

\section{Wheat flour}

Wheat flour is the most common flour used in baking. Wheat flour is a powder made from the grinding of wheat used for human consumption. Wheat varieties are called "soft" or "weak" if gluten content is low, and are called "hard" or "strong" if they have high gluten content.

Hard flour, or bread flour, is high in gluten, with $12 \%$ to $14 \%$ gluten content, and its dough has elastic toughness that holds its shape well once baked. Soft flour is comparatively low in gluten and thus results in a loaf with a finer, crumbly texture.

\section{Rice}

Rice is the seed of the grass species Oryza sativa (Asian rice) or Oryza glaberrima (African rice). As a cereal grain, it is the most widely consumed staple food for a large part of the world's human population, especially in Asia. It is the agricultural commodity with the third-highest worldwide production (rice, 741.5 million ton in 2014), after sugarcane (1.9 billion ton) and maize (1.0 billion ton).

\section{Baking powder}

A simple technique for leavening bread is the use of gas-producing chemicals is baking powder. It is a dry chemical leavening agent, a mixture of a carbonate or bicarbonate and a weak acid and is used for increasing the volume and lightening the texture of baked goods.

Baking powder works by releasing carbon dioxide gas into a batter or dough through an acid-base reaction, causing bubbles in the wet mixture to expand and thus leavening the mixture.

\section{Yeast}

The yeast most commonly used for leavening bread is Saccharomyces cerevisiae, the same species used for brewing alcoholic beverages.

\section{Calcium propionate}

Calcium propionate is used as a preservative in bread and other baked goods, and it may be combined with along with propionic acid and sodium propionate. Calcium propionate helps keep those baked goods fresh by preventing mold and bacterial growth that would cause them to go bad. Calcium propionate also occurs naturally in butter and some type's of cheese.

\section{Vegetable oil}

A vegetable oil is a triglyceride extracted from a plant. Fat provides flavor but more importantly lubricates the dough. This helps to retain the gases released during baking thus ensuring a well risen loaf which will have a soft crumb and will stay fresh longer.

\section{Salt}

Table salt or common salt is a mineral composed primarily of sodium chloride 
$(\mathrm{NaCl})$, a chemical compound belonging to the larger class of salts; salt in its natural form as a crystalline mineral is known as rock salt or halite.

Salt acts as a natural antioxidant in the dough and not only adds taste but especially helps bring out the flavors and aromas present in the flour and other ingredients.

\section{Sugar}

Sweeteners are one of the most important ingredients used in bakery foods. While there are many different sweeteners available, sucrose (or sugar) is perhaps the most versatile.

\section{Milk powder}

Milk or milk powder is not strictly needed in bread recipes. There are many formulas that omit it: the minimal ingredients for a loaf are water, flour and yeast; salt is probably essential for a loaf that is tasty.

\section{Equipment's used}

\section{Sieve}

2. Weighing scale

3. Bread molds

4. Baking ovens

5. Dough scrappers

6. Knives

7. Parchment paper

8. Thermometer

\section{Quality analysis of flour}

\section{Proximate analysis of flour}

\section{Moisture content}

The sample was weighed in an aluminum dish and allowed to dry in a hot air oven maintained at $1100 \mathrm{C}$ for 4 hours until constant weight achieved.

It was cooled in desiccators to room temperature.
Difference in percentage weight was reported as moisture.

Moisture \%, = A - B X $100 / \mathrm{A}-\mathrm{C}$

Where,

$\mathrm{A}=$ Initial weight of sample + Aluminium dish before drying $B=$ Final weight of sample + Aluminium dish after drying $\mathrm{C}=$ Aluminium dish weight

\section{Ash content}

The sample was weighed into silica crucible and placed in muffle furnace at 5500C for 4 hours.

It was cooled in desiccators and weighed. This was repeated until two consecutive weights was constant.

The percent ash content was calculated by on the basis of initial sample.

Ash \% $=(\mathrm{W} 3-\mathrm{W} 1) \mathrm{X} 100 /(\mathrm{W} 2-\mathrm{W} 1)(3.2)$.

Where

$\mathrm{W} 1=$ Weight of silica crucible

W2 = Weight of silica crucible + sample W3

$=$ Weight of silica crucible + ash

\section{Fat content}

The ground sample was weighed accurately in thimble and defatted with petroleum ether in Soxhlet apparatus for 6 hours at700C.

The resultant ether extract was evaporated to remove traces of ether and lipid content was calculated.

\section{Crude fiber content}

The sample was weighed into $500 \mathrm{ml}$ beaker and $200 \mathrm{ml}$ of boiling $0.255 \mathrm{~N}$ sulphuric acid (1.25 percent w/v) was added.

The mixture was boiled for 30 min keeping the volume constant by the addition of hot water at frequent intervals (a glass rod stirred in the beaker helps smooth boiling). 
At the end of this period, the mixture was filtered through a muslin cloth and the residue washed with hot water till free from acid.

The material was then transferred to the same beaker and $200 \mathrm{ml}$ of boiling $0.313 \mathrm{~N}(1.25$ percent w/v) $\mathrm{NaOH}$ was added.

After boiling for 30min., the mixture was filtered to a crucible, dried overnight at 801000C and weighed.

The crucible was kept at in a muffle furnace at 5500C for 3hours.

Then it was cooled in desiccators and weighed again.

The difference in residue weights and ash represents the weight of crude fiber.

\section{Gluten content procedure}

Take the dough from WAP

Place this dough in water for about 1hour

Place it in piece of silk cloth with an aperture of 150 micronsieve

Wash it till the water passing through the silk does not turn blue when a drop of iodine solution is added

Keep in hot air oven at $105^{\circ} \mathrm{C}$ for 4 hours or $130+3^{\circ} \mathrm{C}$ for 120 minute

Remove \& place in a desiccators till cool and weight.

\section{Calculation}

Gluten (on dry basis),

Percent by mass=100 (M2-M1) / M (100-M3)

Where, $\mathrm{M} 1=$ mass in gm of the empty dish,

M2=mass in gm of the dish with dry gluten $\mathrm{M}=$ mass in $\mathrm{gm}$ of the sample.

$\mathrm{M} 3=\%$ age of the moisture in the sample.

\section{Functional properties of flour}

\section{Water absorption power}

Take 25 gm. Of Maida sample

Fill the burette with water

Add the water drop wise \& continuously mix the sample with spathula

Mix the sample with water till the soft dough formed

Record the reading of water used for the preparation of soft dough in burette.

\section{Calculation}

$\%$ age absorption $=$ (volume of water required $\times 100$ ) / weight of sample.

\section{Water absorption capacity}

The water absorption capacity of the flours was determine. One gram of sample mixed with $10 \mathrm{~mL}$ distilled water and allow to stand at ambient temperature $\left(30 \pm 2{ }^{\circ} \mathrm{C}\right)$ for 30 min, the centrifuged for $30 \mathrm{~min}$ at 3,000rpm or $2000 \mathrm{~g}$. Water absorption was examined as percent water bound per gramflour.

\section{Emulsion activity and stability}

The emulsion activity and stability by described and followed as method for the emulsion in present study $(1 \mathrm{~g}$ sample, $10 \mathrm{~mL}$ distilled water) was prepared in calibrated centrifuge tube.

The emulsion was centrifuged at $2000 \times \mathrm{g}$ for 5 min. The ratio of the height of emulsion layer to the total height of the mixture was calculated as emulsion activity in percentage. The emulsion stability was estimated after heating the emulsion contained in calibrated centrifuged tube at $80{ }^{\circ} \mathrm{C}$ for $30 \mathrm{~min}$ in a water-bath, cooling for 15 min under running tap water and centrifuging at $2000 \times \mathrm{g}$ for $15 \mathrm{~min}$. The emulsion stability expressed as 
percentage was calculated as the ratio of the height of emulsified layer to the total height of the mixture.

\section{Foam capacity and foam stability}

The foam capacity (FC) and Foam stability (FS) were determined as described with slight modification. The $1.0 \mathrm{~g}$ flour sample was added to $50 \mathrm{~mL}$ distilled water at $30 \pm 2{ }^{\circ} \mathrm{C}$ in a graduated cylinder. The suspension was mixed and shaken for $5 \mathrm{~min}$ to foam. The volume of foam at $30 \mathrm{~s}$ after whipping was expressed as foam capacity using the formula:

Foam capacity $(\%)=(($ volume of foam AW Volume of foam BW) / volume of foam BW) $\times 100$ Where, $\mathrm{AW}=$ after whipping, $\mathrm{BW}=$ before whipping

\section{Least gelation concentration}

The volume of foam was recorded 1 hour after whipping to determine foam stability as per percent of initial foam volume. The flour dispersions of $2,4,6,8,10,12,14,16,18,20$, 22 , and $30 \%(\mathrm{w} / \mathrm{v})$ prepared in $5 \mathrm{~mL}$ distilled water was heated at $90{ }^{\circ} \mathrm{C}$ for $1 \mathrm{hr}$ in water bath. The contents were cooled under tap water and kept for $2 \mathrm{~h}$ at $10 \pm 2{ }^{\circ} \mathrm{C}$. The least gelation concentration was determined method given as that concentration when the sample from inverted tube did notslip.

\section{Quality analysis of finished products (bread)}

\section{Physical properties}

\section{Loaf weight}

Bread loaves were weighed $20 \mathrm{~min}$ after baking, using a laboratory weighing balance and the readings recorded in papers.

\section{Thickness}

As commercially sliced bread resulted in uniform and somewhat thinner slices, people ate more slices of bread at a time, and ate bread more frequently, because of the ease of eating another piece of bread. This increased consumption of bread and, in turn, increased consumption of spreads, such as jam, to put on the bread.

\section{Water content}

The water absorption of wheat flour dough is governed, in practices, by the protein content and quality and by the extent to which the starch is damaged mechanically.

\section{Sensory evaluation}

In sensory evaluation of bread, all five senses are equally important, as bread samples offer experiences for all of them. In general, all ingredients of the dough, such as flour, salt, sugar and yeast, as well as the production conditions, e.g. kneading, and parameters for leavening and baking in the oven, contribute to the sensory properties of the bread. There is a need for a standardized method to measure bread qualities, including freshness.

This procedure points out the sensory properties contributing to bread quality, and describes the main steps of the protocol, which need to be applied in sensory evaluation of bread. The procedure describes analytical sensory evaluation of bread carried out in a sensory laboratory with a trained panel. 


\section{Plan of work}

\section{Flow sheet of rice flour preparation}

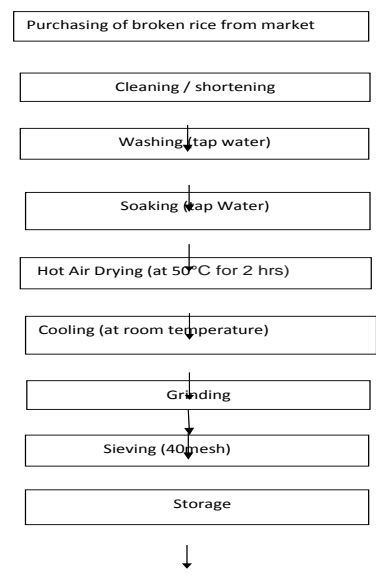

Flow sheet of bread preparation

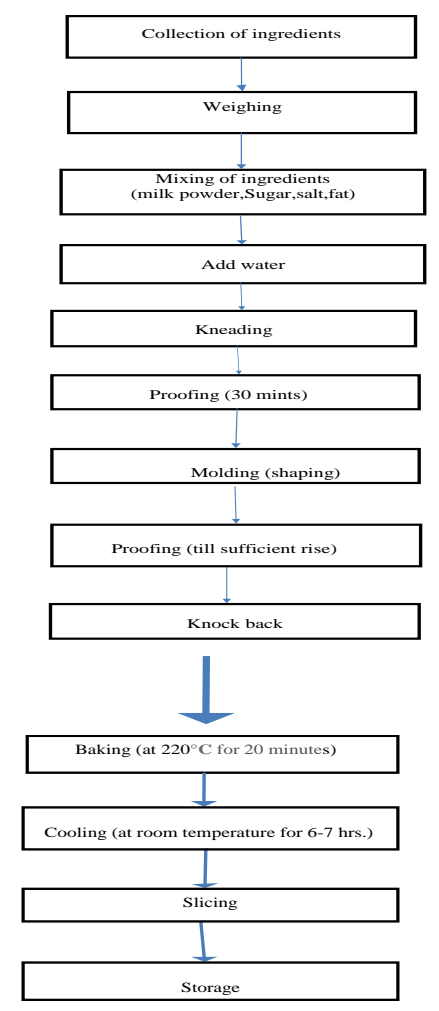

\section{Results and Discussion}

Analysis (proximate analysis, functional properties) of wheat and rice flour reading is given in different table 1-6 and analysis (physical analysis, sensory evaluation) of control sample and different composition of bread. There are also determined the texture 
profile analysis of prepared breads are shown in figure 2 to figure 9.

\section{Analysis of flours}

Before preparation of bread by flour, moisture content of wheat-flour, rice-flour were analyzed and found as $13.28 \%, 11.22 \%$ respectively. The moisture content for wheat and rice flours are presented in Table 3 which ranged from $11.22 \%$ to $13.28 \%$ depending upon the moisture absorb. From the Table 3, it is clear that the moisture content of rice flour decreased with wheat flour the moisture content highly affected in preservation of bread. Ash content of wheat flour, rice flour were analyzed and found as $0.39 \%, 0.47 \%$ respectively.

The ash content for wheat and rice-flour are presented in Table 3 which ranged from 0.09 to $0.07 \%$.Fiber content of wheat flour, rice flour were analyzed and found as $0.50 \%$,
$0.79 \%$ respectively. Rice flour is gluten-free Gluten is a protein found in wheat, oats, barley and rye. The specific agent in gluten that causes the condition known as celiac disease is gliadin, which is rich in the amino acids proline and glutamine. Gluten content of wheat flour is analyzed $12 \%$.

In Table $3 \mathrm{WAP}=$ Water Absorption Power, $\mathrm{OAC}=$ Oil Absorption Capacity, WAC $=$ Water Absorption Capacity, $\mathrm{FC}=$ Foaming Capacity, $\mathrm{FS}=$ Foaming Stability, $\mathrm{EA}=$ Emulsion Activity, LGC $=$ Least Gelation Concentration.

Functional properties of wheat flour \& rice flour are shows in the table 3 . In table 3 there are some functional properties of both wheat and rice flour is differ because the difference in constitutes of both wheat and rice flour. Water absorption power of rice flour is less compare to wheat flour.

Table.1 Formulation table of rice bread

\begin{tabular}{|l|c|c|c|c|c|c|c|c|}
\hline S.No. & $\begin{array}{c}\text { Wheat } \\
\text { flour }(\mathbf{g m})\end{array}$ & $\begin{array}{c}\text { Rice } \\
\text { Flour } \\
(\mathbf{g m})\end{array}$ & $\begin{array}{c}\text { Yeast } \\
\mathbf{( g m})\end{array}$ & $\begin{array}{c}\text { Salt } \\
\mathbf{( g m )}\end{array}$ & $\begin{array}{c}\text { Sugar } \\
\mathbf{( g m )}\end{array}$ & $\begin{array}{c}\text { Vegetable fat } \\
\mathbf{( g m )}\end{array}$ & $\begin{array}{c}\text { Calcium } \\
\text { propionate (gm.) }\end{array}$ & $\begin{array}{c}\text { Water } \\
(\mathbf{m l})\end{array}$ \\
\hline Control & 250 & 0 & 10 & 5 & 7.5 & 5 & 1 & 1 \\
\hline Sample 1 & 125 & 125 & 20 & 5 & 7.5 & 5 & 162.5 \\
\hline Sample 2 & 100 & 150 & 20 & 5 & 7.5 & 5 & 1 & $\mathbf{1 6 2 . 5}$ \\
\hline Sample 3 & 75 & 175 & 20 & 5 & 7.5 & 5 & 1 & $\mathbf{1 6 2 . 5}$ \\
\hline Sample 4 & $\mathbf{5 0}$ & $\mathbf{2 0 0}$ & $\mathbf{2 0}$ & $\mathbf{5}$ & $\mathbf{7 . 5}$ & $\mathbf{5}$ & $\mathbf{1}$ & $\mathbf{1 6 2 . 5}$ \\
\hline
\end{tabular}

Table. 2 Proximate analysis

\begin{tabular}{|c|c|c|c|c|c|c|}
\hline Sample & $\begin{array}{c}\text { Moisture } \\
\text { \% }\end{array}$ & $\begin{array}{c}\text { Ash } \\
\text { \% }\end{array}$ & Fiber\% & $\begin{array}{c}\text { Gluten } \\
\text { content \% }\end{array}$ & $\begin{array}{c}\text { Protein } \\
\text { \% }\end{array}$ & Fat\% \\
\hline $\begin{array}{c}\text { Wheat } \\
\text { flour }\end{array}$ & 13.28 & 0.39 & 0.50 & 12 & 15.74 & $\mathbf{2 . 7 2}$ \\
\hline Rice flour & $\mathbf{1 1 . 2 2}$ & $\mathbf{0 . 4 7}$ & $\mathbf{0 . 7 9}$ & $\mathbf{0}$ & $\mathbf{7 . 2 3}$ & $\mathbf{2 . 7 9}$ \\
\hline
\end{tabular}


Table.3 Functional properties analysis of wheat flour and rice flour

\begin{tabular}{|c|c|c|}
\hline Functional properties & Wheat flour & Rice flour \\
\hline WAP \% & 62.40 & $\mathbf{5 5 . 4 0}$ \\
\hline OAC \% & 146.00 & $\mathbf{1 8 3}$ \\
\hline WAC \% & 144.20 & $\mathbf{1 7 8}$ \\
\hline FC \% & 12.92 & $\mathbf{1 4 . 4 5}$ \\
\hline FS \% & 1.94 & $\mathbf{4 . 2 0}$ \\
\hline EA \% & 44.12 & $\mathbf{4 9}$ \\
\hline LGC \% & $\mathbf{8}$ & $\mathbf{1 0}$ \\
\hline
\end{tabular}

Table.4 Physical properties

\begin{tabular}{|c|l|c|c|c|}
\hline S.N. & Sample & $\begin{array}{c}\text { Loaf } \\
\text { Weight } \\
(\mathbf{g m} .)\end{array}$ & $\begin{array}{c}\text { Thckness } \\
(\mathbf{m m})\end{array}$ & $\begin{array}{c}\text { Water Content } \\
(\mathbf{m l})\end{array}$ \\
\hline $\mathbf{1 .}$ & Control & 552 & 15 & $\mathbf{1 6 5 . 8 0}$ \\
\hline $\mathbf{2 .}$ & $50 \%$ rice & 555 & 15 & $\mathbf{1 6 0}$ \\
\hline $\mathbf{3 .}$ & $60 \%$ rice & 555 & 15 & $\mathbf{1 6 0}$ \\
\hline $\mathbf{4 .}$ & $70 \%$ rice & 556 & 15 & $\mathbf{1 6 0}$ \\
\hline $\mathbf{5 .}$ & $\mathbf{8 0 \%}$ rice & $\mathbf{5 5 7}$ & $\mathbf{1 5}$ & $\mathbf{1 6 0}$ \\
\hline
\end{tabular}

Table.5 Texture profile analysis of experimental rice bread and wheat bread

\begin{tabular}{|c|c|c|}
\hline Types of bread & Hardness $(\mathbf{k g})$ & Cohesiveness \\
\hline $\begin{array}{c}\text { Whole wheat bread } \\
\text { (control sample) }\end{array}$ & 0.09 & $\mathbf{0 . 6 9}$ \\
\hline Bread (50\% of rice flour) & 1.37 & $\mathbf{0 . 5 0}$ \\
\hline Bread (60\% of rice flour) & 1.29 & $\mathbf{0 . 3 2}$ \\
\hline Bread (70\% of rice flour) & 1.66 & $\mathbf{0 . 3 2}$ \\
\hline Bred (80\% of rice flour) & $\mathbf{1 . 7 6}$ & $\mathbf{0 . 0 2}$ \\
\hline
\end{tabular}

Table.6 Sensory evaluation

\begin{tabular}{|c|c|c|c|c|c|}
\hline Sample No. & Colour & Appearance & Taste & Aroma & $\begin{array}{c}\text { Overall } \\
\text { Acceptability }\end{array}$ \\
\hline 1. & 8 & 8 & 8.5 & 7.5 & $\mathbf{8}$ \\
\hline 2. & 8 & 7 & 7 & 6 & $\mathbf{7}$ \\
\hline $\mathbf{3 .}$ & 8 & 7 & 7 & 6 & $\mathbf{7}$ \\
\hline $\mathbf{4 .}$ & 7.5 & 6.5 & 6.5 & 6 & $\mathbf{6 . 6}$ \\
\hline $\mathbf{5 .}$ & $\mathbf{7 . 5}$ & $\mathbf{6}$ & $\mathbf{6 . 5}$ & $\mathbf{6}$ & $\mathbf{6 . 6}$ \\
\hline
\end{tabular}


Fig.1 Control sample
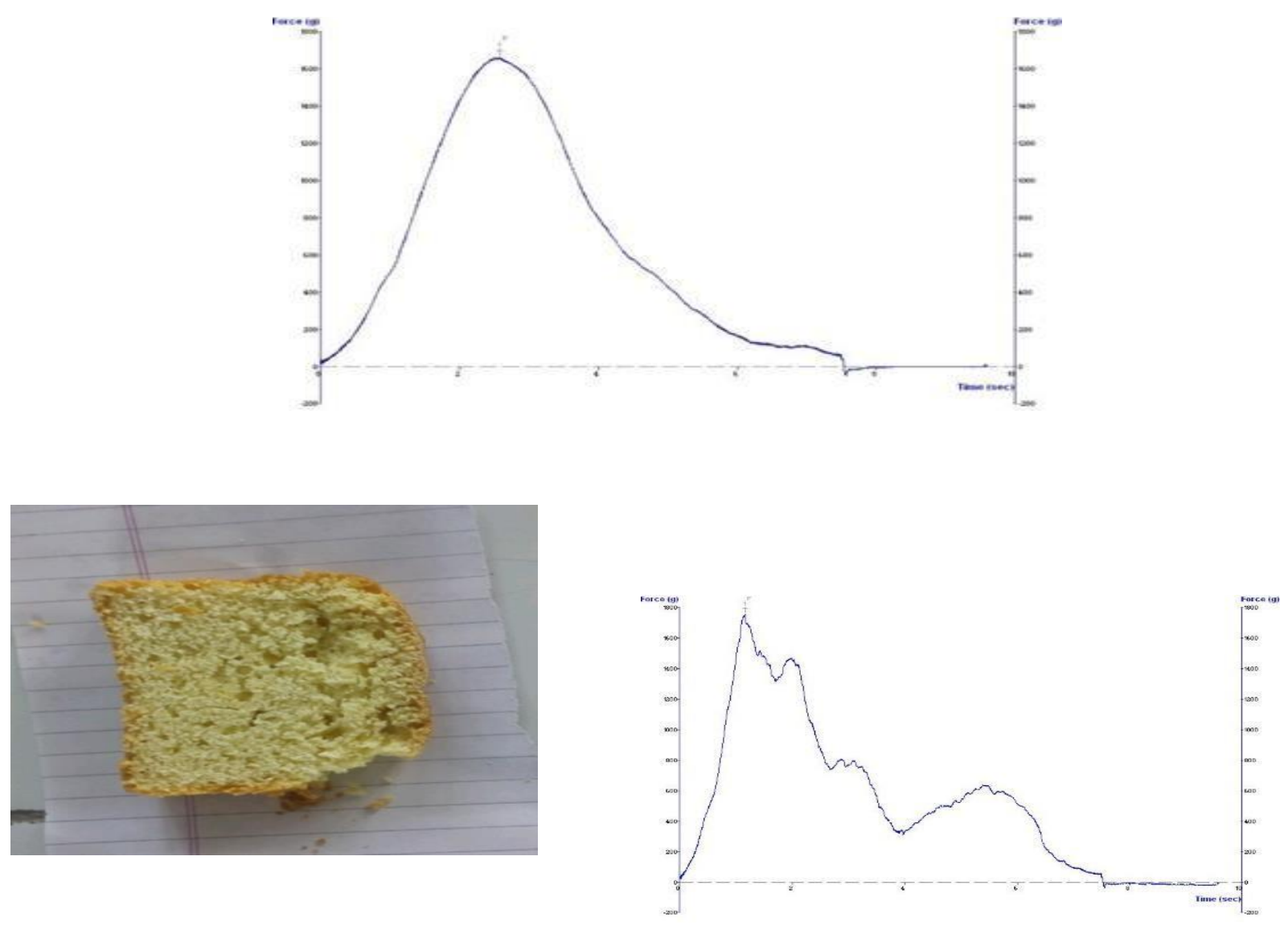

Figure 2: Bread slice, composition by $50 \%$ wheat flour

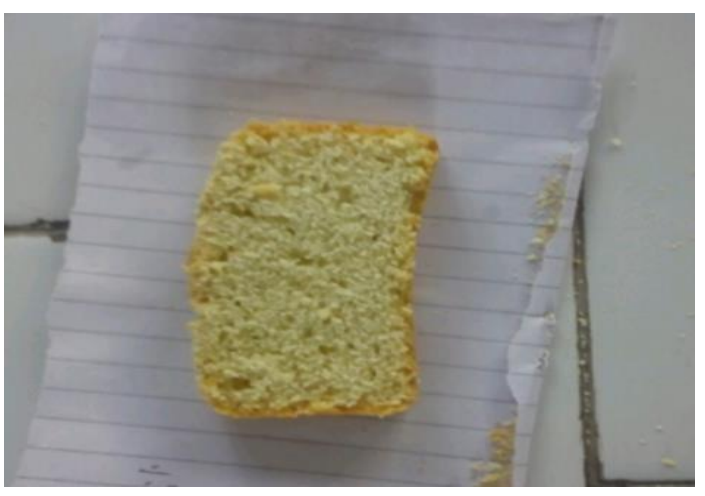

Figure 4: Bread slice composition by $40 \%$ wheat flour $\& 60 \%$ rice flour.
Figure 3: shows texture analysis graph for figure 2 bread slice flour bread

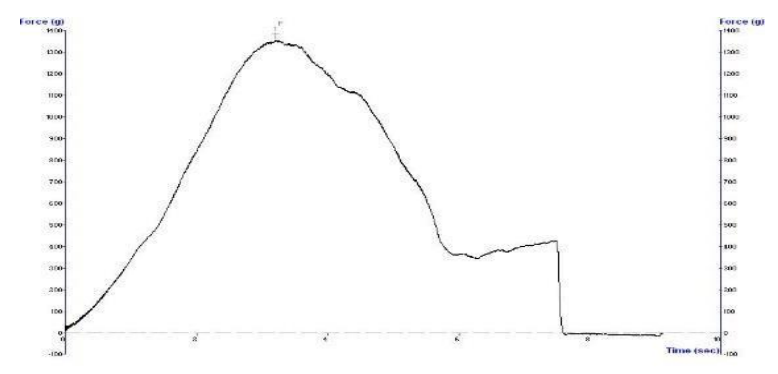

Figure 5: shows Texture analysis graph for figure 4 bread slice 


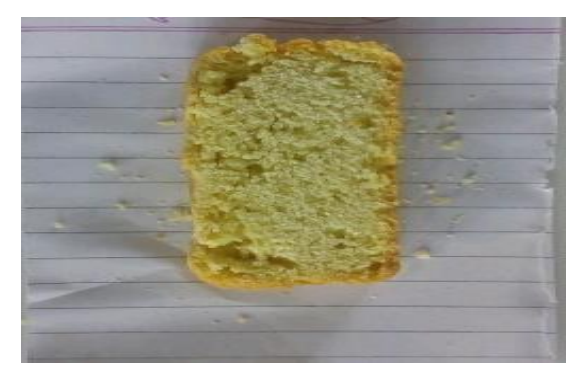

Figure 6: Bread slice composition by $30 \%$ wheat flour $\& 70 \%$ rice flour.

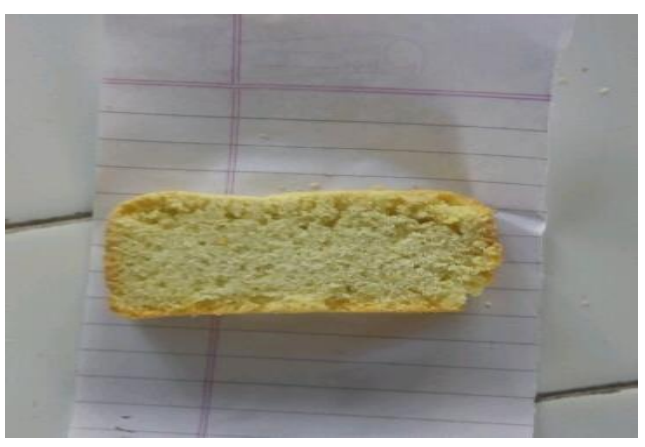

Figure 8: Bread slice composition by $20 \%$ wheat flour $\& 80 \%$ rice

Oil absorption capacity, foaming capacity, foaming stability elastic stability and least gelation concentration is more than the wheat flour.

\section{Quality analysis of finished product}

Physical properties of the bread show difference between control sample and composition of different rice bread. The loaf weight is determined by the weighing balance, there is difference in weight from adding rice flour. Thickness of composition of rice bread is similar to the control sample about $15 \mathrm{~mm}$ and the standard thickness of is $12.7 \mathrm{~mm}$. Water content of control sample is $162.80 \mathrm{ml}$ and composition of rice bread is $160 \mathrm{ml}$ because that the water absorption power of rice flour is less compare to the wheat flour, so in composition of rice flour bread add less water.
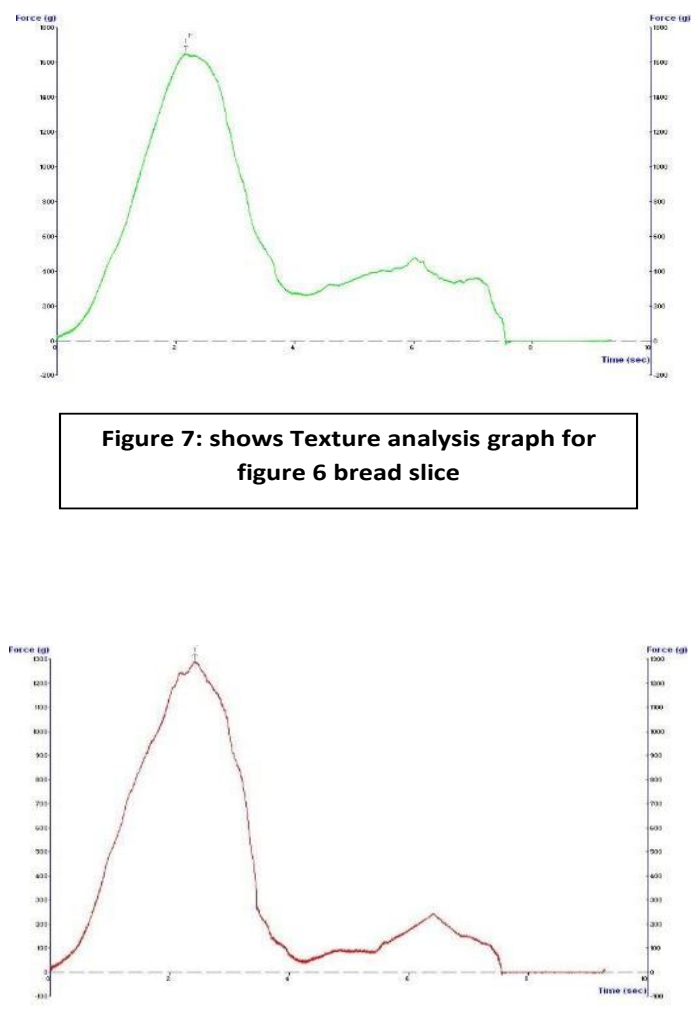

Figure 9: shows Texture analysis graph for figure 8 bread slice.

\section{Texture profile analysis}

Textural profile analysis testing is also known as the "Two Bite Test". The test mimics the mouth's biting activity allowing analysis of how food responds when chewed. The Two Bite testing method allows for multiple textures to be analyzed in one test. The force vs time graph shows the force peak resulting from each compression cycle. This is a typical 2-cycle TPA curve obtained from any load bearing instrument.

The texture analysis analyzed by the TPA (Texture Profile Analyzer).

In figure 1 texture analysis profile shows the how much hardness occurs in wheat bread.

The hardness of wheat bread (fig1 control sample) is about $0.09 \mathrm{~kg}$

Table 5 showed the hardness and cohesiveness of wheat bread (control sample) $\&$ different composition of rice flour bread. 
Hardness is increased with increasing the percentage of rice flour, means the hardness of bread is high compare to the wheat bread (control sample).

Sensory analysis of developed rice flour breads as compared to a control sample and commercially marketed bread as evaluated by gluten-free and non-restricted diet for consumers. By the sensory evaluation of prepared bread to determine the color, appearance, taste aroma and overall acceptability is shown in table 6 .

In conclusion the general population could be used for a gluten-free consumer study because there is potential for any typical consumer to be diagnosed with celiac disease and gluten intolerance, however bias related to the color and appearance of the samples could heavily skew results. So, the main aim of the current study was to develop gluten free bread which provides additional health benefits. In current research, rice flour was incorporated in Bread which is a convenient food and can be readily consumed by people of all age groups.

Broken rice flour was incorporated at levels $20,30,40, \& 50$ percent in wheat flour. Effect of rice flour addition on sensory properties of flour, nutritional properties of flour, baking quality of bread and textural properties mainly hardness and compressibility for bread, respectively, were studied.

There was significant decrease in the water absorption (\%) as the level of rice flour increase.

There was increase in the development time of the dough with rice flour addition.

Organoleptic scores for bread with $60 \%$ level for rice flour had the highest acceptability scores.

Nutrient analysis of breads showed overcome celiac disease cause by gluten content present in wheat flour.
Texture profile analysis showed little difference the same force Vs time plot.

It is also observed that addition of up to $50 \%$, $60 \%, 70 \%$ and $80 \%$ rice flour does not negatively affect the sensory scores.

\section{References}

AnaCristina Ballesteros López; Accacia Julia Guimarães Pereira; Roberto Gonçalves Junqueira. (2004). Flour mixture of rice flour, corn and cassava starch in the production of gluten- free white bread. Journal of Brazilian Archives of Biology and Technology vol.47:3.

Annika Olsson and C. Skjoldebrand. (2008). Risk management and quality assurance through the food supply chain. Journal of Food Science. vol. $2: 3$

Arpita Das, Utpal Raychaudhuri, and Runu Chakraborty. (2011). Cereal based functional food of Indian subcontinent: a review. Journal of Food Science \& Technology. Vol. 49(6):2.

Arun Chandrashekar and H. Mazhar; The Biochemical Basis and Implications of Grain Strength in Sorghum and Maize. Journal of Cereal Science vol.30 (3):3.

Hardeep Singh Gujral, Ignacio Guardiola, José Vicente Carbonell, and Cristina M. Rosell. (2003). Effect of Cyclodextrin as on Dough Rheology and Bread Quality from Rice Flour. Journal of Agriculture \& Food Chemistry. vol. 51(13):1.

Lynda Dykes, Lioyd W Rooney, Ralph D Wanishka, William Rooney. (2015). Phenolic Compounds and Antioxidant Activity of Sorghum Grains of Varying Genotypes. Journal of Agricultural and Food Chemistry53 (17): 1 .

Umadevi, M., R. Pushpa1, K.P. Sampathkumar, Debjit Bhowmik. 
(2014). Rice-Traditional Medicinal Plant in India. Journal of Pharmacognosy and Phytochemistry. Vol. 24:5.

MyoungHo Kim. (2013). Review on Rice Flour Manufacturing and Utilization. Journal of Biosystems Engineering. vol38 (2):4.

Ratnavathi CV, Patil JV. (2013). Sorghum Utilization as Food. Journal of Nutrtion of Food Science. vol.4:2

Ranasalva N and Visvanathan. (2014). Development of Bread from Fermented Pearl Millet Flour. Journal of Food Process Technology vol. 21(3): 2.

Suresh Chandra and Samsher; (2013). Assessment of functional properties of different flours; African Journal of Agricultural Research.vol.8 (38):4.

Tharise, N, Julianti, E. and Nurminah, M. (2014). Evaluation of physicochemical and functional properties of composite flour from cassava, rice, potato, soybean and xanthan gum as alternative of wheat flour. International Food Research Journal. vol21:3.

Uma Ballolli, UshaMalagi, NirmalaYenagi, Valerie Orsati and YuvanGariepy; February, (2014) Development and quality evaluation of foxtail millet [Setaria italica (L.)] incorporated breads; Karnataka Journal of Agriculture Science. vol27:3

\section{How to cite this article:}

Bhanu Pratap Singh and Pradeep Srivastava. 2020. Quality Analysis of Prepared Mixed Wheat Flour Int.J.Curr.Microbiol.App.Sci. 9(12): 1510-1525. doi: https://doi.org/10.20546/ijcmas.2020.912.180 